\title{
Protective Effect of Melatonin on Carbon Tetrachloride - induced Hepatic Fibrogenesis in Rats
}

\author{
Mona F. El-Karn \\ Medical Physiology Department, Faculty of Medicine, Assiut University
}

\begin{abstract}
Background: Liver cirrhosis is a critical stage of chronic liver diseases that can produce liver failure, portal hypertension and hepatic carcinoma. Sustained oxidative stress plays a key role in cell damage and fibrosis induced during liver cirrhosis. Aim of the work: The aim of the present study was to examine the potential protective effect of exogenous melatonin co-treatment on liver tissue injury and oxidative stress processes during induction of early phase of liver fibrosis by carbon tetrachloride $\left(\mathrm{CCl}_{4}\right)$ injection in rats. Methods: Hepatic fibrogenesis model was induced in this study by subcutaneous injection of rats by carbon tetrachloride $\left(\mathrm{CCl}_{4}\right)$. Eighteen adult, female albino rats were randomly divided into 3 groups $(n=6)$ : control group (group I), carbon tetrachloride treated group (group II) and $\mathrm{CCl}_{4}+$ melatonin cotreated group (group III). Rats in $\mathrm{CCl}_{4}$ treated group were injected subcutaneously with sterile $\mathrm{CCl}_{4}(2 \mathrm{ml} / \mathrm{kg}$ of body weight) in a ratio of 1:1 with olive oil twice a week for 8 weeks. Rats of group III (melatonin co-treated group) were injected with $\mathrm{CCl}_{4}$ in the same manner as in group II and received intraperitoneal melatonin injection in a dose of $20 \mathrm{mg} / \mathrm{kg}$ twice a week for 8 weeks, starting from the beginning of $\mathrm{CCl}_{4}$ injection. Rats in normal control group were injected subcutaneously with olive oil at the same dose and frequency as those in $\mathrm{CCl}_{4}$ treated group. At the end of the experiment, rats were sacrificed, blood samples were collected for biochemical assay. Liver from each animal was removed for histopathological examination. Measurement of oxidative stress markers in serum was done by chemical estimation of serum levels of free radicals: lipid peroxides (LPO) and nitric oxide (NO). Antioxidant enzymes were estimated by chemical measurement of glutathione peroxidase (GSH-Px) and superoxide dismutase (SOD) in the serum. Liver injury was assessed by evaluation of serum levels of liver enzymes (alanine aminotransferase (ALT), and aspartate aminotransferase (AST)). Determination of development of early phase of hepatic fibrogenesis was done by chemical measurement of serum level of hyaluronic acid (HA) using enzyme immunoassay (ELISA), and by histopathological examinations of hepatic tissues to detect early fibrotic changes as well as other histological damage of hepatic tissue caused by $\mathrm{CCl}_{4}$ injection with or without melatonin administration. Results: Results of the present study showed that $\mathrm{CCl}_{4}$ treatment to rats of group II caused highly significant increase in serum levels of oxidative stress markers (lipid peroxides and nitric oxide), decrease in serum levels of antioxidant markers (glutathione peroxidase and superoxide dismutase), increase of serum levels of hepatic enzymes (ALT and AST) as well as increased serum level of hyaluronic acid (HA) 8 weeks after $\mathrm{CCl}_{4}$ injections when compared with control group. Melatonin co-treatment to animals of group III caused significant reduction in
\end{abstract}


serum levels of lipid peroxides (LPS) and nitric oxide (NO), significant increase in plasma levels of glutathione peroxidase (GSH-Px) and superoxide dismutase (SOD), significant reduction in serum levels of liver enzymes (ALT and AST) as well as significant decrease in serum level of hyaluronic acid (HA) 8 weeks after $\mathrm{CCl}_{4}$ injections when compared with group II. Histopathological study of liver tissue of animals of $\mathrm{CCl}_{4}$ treated group showed various manifestation of hepatic cell damage and early phase of fibrogenesis as necrosis, degeneration, collagen deposition and few fibrous threads extending into the hepatic lobules. Histopathological study of hepatic tissue of melatonin co-treated group showed that melatonin caused marked amelioration of histological manifestations of hepatic cell degeneration and absence of any sign of fibrogenesis with nearly normalization of the histological appearance of the hepatic tissue. Compared with $\mathrm{CCl}_{4}$ treated group (group II), histological appearance of hepatic tissue of rats in melatonin co-treated group (group III) showed significant improvement. Conclusion: Results of this study suggest that melatonin has a substantial hepatoprotective effect in a rat hepatic fibrosis model induced by an 8weeks' $\mathrm{CCl}_{4}$ regimen. The protective effect of melatonin may be due to both its direct radical scavenging properties and indirect effect as a regulator of antioxidant systems. Therefore, the study proposes that melatonin may be a valuable drug for inhibition of unwanted fibrosis in patients exposed to different hepatotoxic agents.

\section{INTRODUCTION}

Liver diseases have a variety of causes such as infections, parasites, nutrition deficiency, inborn errors, toxic substances and malignancy. Viral hepatitis is the major cause of liver disease in tropical areas including Egypt $^{(\mathbf{1})}$. Liver fibrosis results from sustained activation of hepatic stellate cells (HSC) by oxidative stress and cytokines. It replaces damaged cells with an extracellular matrix (2). If treated properly at fibrosis stage, cirrhosis can be prevented ${ }^{(3)}$. Liver cirrhosis is a critical stage of chronic liver diseases that can produce liver failure, portal hypertension and hepatocarcinoma. It is related to high morbidity/mortality rate. The induction of oxidative stress, mitochondrial dysfunction and depletion of antioxidant status is a relevant feature in the progression of liver cirrhosis and fibrosis ${ }^{(4,5)}$. The current treatments of liver cirrhosis are limited to the removal of the underlying injurious stimulus, e.g. viruses in cases involving viral hepatitis. However, no effective antifibrosis drugs are available at present ${ }^{(6)}$.

Carbon tetrachloride $\left(\mathrm{CCl}_{4}\right)$ is widely used to induce hepatic fibrosis and cirrhosis in animal models ${ }^{(7)}$. In the past years, carbon tetrachloride was widely used as a dry cleaning solvent until it was recognized as a carcinogen. Today, it is primarily used as an organic solvent and thousands of workers are potentially exposed to this chemical ${ }^{(8)}$. Oxidative stress, free radical generation and lipid peroxidation have been postulated to participate in the molecular mechanism of $\mathrm{CCl}_{4}$ induced hepatotoxicity ${ }^{(9)}$. Liver cell injury induced by carbon tetrachloride involves initially the metabolism of carbon tetrachloride to 
trichloromethyl free-radical by the mixed function oxidase system of the endoplasmic reticulum ${ }^{(\mathbf{1 0})}$.This trichloromethyl free radical $\left(\mathrm{CCl}_{3}\right)$, reacts rapidly with molecular oxygen to produce the trichloromethyl peroxyl radical $\left(\mathrm{CCl}_{3} \mathrm{O}_{2}\right)$ and that these highly toxic radicals are responsible for attacks on unsaturated fatty acids of phospholipids present in the cell membrane, leading to lipid peroxidation in the liver cells ${ }^{(11)}$. In this regard, the reduction of oxidative stress may be a useful approach to reduce cell injury, cirrhosis and fibrosis induced by $\mathrm{CCl}_{4}$ in experimental models of liver fibrosis (12,13). Many reports indicate that $\mathrm{CCl}_{4}$ causes necrosis, fibrosis, mononuclear cell infiltration, steatosis and foamy degeneration of hepatocytes, increase in mitotic activity and cirrhosis in the liver ${ }^{(\mathbf{1 4}, \mathbf{1 5}, \mathbf{1 6})}$. $\mathrm{CCl}_{4}$ has also been reported to cause apoptosis in liver cells ${ }^{(15,17,18,19)}$.

Several lines of evidence suggest that oxidative stress plays an important role in the etiopathogenesis of hepatic fibrosis ${ }^{(\mathbf{2 0 , 2 1})}$. In attempting to limit the oxidative damage effect on hepatic cells, a number of antioxidants have been tested in experimental hepatic fibrosis models ${ }^{(22)}$. Melatonin (N-acetyl-5-methoxy-tryptamine), a lipophilic indoleamine derived from tryptophan, was long thought to be produced exclusively in the pineal gland, but it has recently been detected in many other tissues. It regulates circadian rhythms, sleep and immune system activity, and behaves as a free radical scavenger ${ }^{(23)}$. It also exerts cytoprotection in various experimental models of liver injury (24,25). Melatonin has been proved to have the greatest impact not only on oxidative stress, but also on systems of defense against free radicals, restoring the oxidative balance in treated experimental animals ${ }^{(\mathbf{2 2 , 2 6 )}}$.

\section{Aim of the work:}

The aim of the present study was to examine the potential protective effect of exogenous melatonin cotreatment on liver tissue injury and oxidative stress processes during induction of early phase of liver fibrosis by carbon tetrachloride $\left(\mathrm{CCl}_{4}\right)$ injection in rats. Therefore, the current study investigated the changes in oxidative processes, liver enzymes and serum marker of fibrosis with or without melatonin administration to CCL4 treated rats. Additionally, a detailed histopathological examination of hepatic tissues of all rat groups was performed to study effect of melatonin administration on histological damage caused by $\mathrm{CCl}_{4}$ injection.

\section{MATERIALS \& METHODS}

\section{Reagents:}

Nacetyl-5-methoxytryptamine (melatonin) was purchased from Sigma-Aldrich GmbH, Germany. Carbon tetrachloride $\left(\mathrm{CCl}_{4}\right)$ obtained from El-Gomhorya Company, Cairo, Egypt. Kits for Hyaluronic Acid (HA) was supplied by New Test Company, Hyaluronic Acid (HA) test kit (Guechot et al., 2000) $^{(27)}$. All other reagents were of analytical grade.

Animals:

Eighteen adult, female albino rats weighing 160-200 gram were obtained from the Animal House of Faculty of Medicine of Assiut University. Rats were housed in groups in temperature and humidity regulated room, with 
free access to food and water. They were randomly divided into 3 groups $(n=6)$ : control group (group I), carbon tetrachloride $\left(\mathrm{CCl}_{4}\right)$ treated group (group II) and $\mathrm{CCl}_{4}+$ melatonin co-treated group (group III). Rats in $\mathrm{CCL}_{4}$ treatment groups were injected subcutaneously with sterile $\mathrm{CCl}_{4}$ (2 $\mathrm{ml} / \mathrm{kg}$ of body weight) in a ratio of $1: 1$ with olive oil twice a week for 8 weeks. Rats of group III injected with $\mathrm{CCl}_{4}$ in the same manner as in group II and received intraperitoneal melatonin injection in a dose of 20 $\mathrm{mg} / \mathrm{kg}$ twice a week for 8 weeks, starting from the beginning of $\mathrm{CCl}_{4}$ injection. Rats in normal control group subcutaneously injected with saline and olive oil (in a ratio of 1:1) at the same dose and frequency as those in $\mathrm{CCl}_{4}$ treated group.

After 8 weeks, all animals were sacrificed. An immediate laparotomy was performed for each animal in all groups. Blood was drawn from the abdominal aorta and livers were removed from all animals. Blood was collected into tubes and centrifuged. Serum was aspirated and frozen at $20{ }^{\circ} \mathrm{C}$ until time of biochemical assay. Liver tissue was fixed in formalin and embedded in paraffin. Thin sections of hepatic tissues were obtained for histopathological evaluation of the damage caused by $\mathrm{CCl}_{4}$ injection with or without melatonin administration.

(A) Biochemical determination:

(1) Measurement of oxidative stress markers in serum:

This was done by estimation of serum levels of free radicals: lipid peroxides (LPO) and nitric oxide (NO):

- Determination of serum level of lipid peroxides (LPO): Serum level of lipid peroxides (LPO) was measured as thiobarbituric acid reactivity (TBARS). The product of the reaction between malondialdehyde and thiobarbituric acid was measured as described by Thayer $\mathbf{( 1 9 8 5 )}^{(\mathbf{2 8})}$.

- Nitric oxide (NO) level in the serum was determined by the method of Van Bezooijen et al. (1998) $^{(29) .}$

(2) Measurement of antioxidant markers in serum:

This was done by estimation of serum levels of antioxidant enzymes: glutathione peroxidase (GSH-Px) and superoxide dismutase (SOD):

- Serum glutathione peroxidase (GSH-Px) level in the serum was determined chemically as described by Ellman (1959) ${ }^{(\mathbf{3 0})}$.

- Superoxide dismutase (SOD) level in the serum was determined according to the method of Misra and Fridovich (1972) ${ }^{(31)}$.

(3) Analysis of liver enzymes:

$\begin{array}{lr}\text { Serum levels of alanine } \\ \text { aminotransferase (ALT) } & \text { and } \\ \text { aspartate aminotransferase } & \text { (AST) } \\ \text { were measured with routine } & \text { rathedic } \\ \text { laboratory methods by } & \text { kinetic } \\ \text { method (Breuer J, 1996) } & \text { (32). }\end{array}$

(4) Measurement of serum hyaluronic acid (HA):

Estimation of serum Hyaluronic Acid (HA) by enzyme immunoassay (EIA) using Hyaluronic Acid (HA) Test Kit as described by Guechot et al. $(2000)^{(27)}$.

(B) Histopathological examination:

All sections of liver tissues were stained with Hematoxylin and Eosin (H\&E) according to Drury and Wallington (1980) ${ }^{(\mathbf{3 3})}$ for detection of 
histological manifestations of hepatic cell damage as well as detection of early fibrogenesis caused by $\mathrm{CCl}_{4}$ injection with or without melatonin administration.

Statistical analysis:

Simple descriptive statistical tests; Mean \pm Standard Error (SE) were used to describe the numerical values of the sample. Student t-test was used to compare between two groups. Sperman correlation test was also used with a range from -1 to 1 . A difference was considered significant at probability of $\mathrm{p}<0.05$, highly significant at $p<0.01$ and very highly significant at $\mathrm{p}<0.001$.

\section{RESULTS}

Effect of melatonin administration on oxidative stress markers after $\mathbf{C C l}_{4}$ injection:

$\mathrm{CCl}_{4}$ treated group (group II) showed marked increase in serum levels of oxidative stress markers as reflected by a highly significant increase in mean values of lipid peroxides and nitric oxide $(p<0.001$ for each), 8 weeks after $\mathrm{CCl}_{4}$ injection when compared with control group (group I). Melatonin co-treatment to animals of group III caused significant reduction in serum levels of lipid peroxides and nitric oxide $(p<0.001$ and $<0.01$ for each parameter respectively) when compared by group II $(p<0.001$ for each). Comparing results of melatonin cotreatment group (group III) with those of control one (group I) showed non significant increase $(p>0.05)$ for LPO level, at the same time, NO serum level still showing significant increase $(p<0.05)$ when compared to level of control group (Table1).

Effect of melatonin administration on antioxidant markers after $\mathbf{C C l}_{4}$ injection:

$\mathrm{CCl}_{4}$ treated group (group II) showed a very highly significant reduction in antioxidant markers as serum levels of GSH-Px and superoxide dismutase $(\mathrm{p}<0.001$ for each), 8 weeks after $\mathrm{CCl}_{4}$ injection when compared with control group (group I). Melatonin co-administration to animals of group III caused a significant increase in plasma levels of glutathione peroxidase (GSH-Px) and superoxide dismutase when compared by group II $(\mathrm{p}<0.001$ for each). Comparing results of melatonin treatment group (group III) with those of control one showed non significant difference ( $p>0.05)$ for GSH-Px level, at the same time, SOD serum level still showing significant decrease $(p<0.05)$ comparing to levels of control group (Table 2).

Effect of melatonin administration on liver enzymes after $\mathbf{C C l}_{4}$ injection:

Estimation of serum level of hepatic enzymes (ALT and AST) showed very highly significant increase $(p<0.001$ for each) in mean serum level of ALT and AST in $\mathrm{CCl}_{4}$ treated group (group II) as compared with the control group. Melatonin cotreatment to animals of group III caused significant reduction in ALT and AST enzymes when compared by group II $(p<0.001$ for each $)$. Melatonin co-treated group still showing significant increased liver enzymes $(p<0.05)$ as compared to control group (Table 3). 
Effect of melatonin administration on serum level of hyaluronic acid (HA) after $\mathrm{CCl}_{4}$ injection:

Measurement of serum HA showed significantly higher level in $\mathrm{CCl}_{4}$ treated group (group II) than in normal control group $(\mathrm{P}<0.001)$. Melatonin co-treatment to animals of group III caused a significant reduction in serum level of HA $(p<0.001)$ when compared by group II. Also, rats of group III showed non significant increase $(p>0.05)$ in serum level of HA as compared with that of the control group (Graph 1). Also, Table (4) showed very highly significant positive correlation between $\mathrm{HA}$ and liver enzymes (ALT\&AST) $(\mathrm{P}<0.001)$.

Effect of melatonin administration on histopathological changes of hepatic tissues caused by $\mathrm{CCl}_{4}$ injection:
At the end of the experiment, liver tissue samples from control rats (group I) showed normal lobular architecture with central veins and radiating hepatic cords (Figure I). Liver tissue samples from group II ( $\mathrm{CCl}_{4}$ treated group) showed hepatic cell degeneration, necrosis, collagen deposition and venous engorgement in the microcirculatory bed. Scattered fibrous threads appear every now and then in-between hepatic lobules (Figure 2). In group III $\left(\mathrm{CCl}_{4}+\right.$ melatonin treated group) however, hepatocyte degeneration, necrosis and infiltration of inflammatory cells were all apparently ameliorated. Collagen deposition was also markedly reduced with no apparently formed fibrous threads with normalization of the appearance of the microvascular bed (Figures 3). Compared with group II, the histological picture of the liver tissue of rats in melatonin co-treated group was significantly improved.

Table (1): Effect of melatonin co-treatment on serum level of oxidative stress markers (LPO\&NO) $(\mu \mathrm{mol} / \mathrm{L})$ in CCL4 treated rats

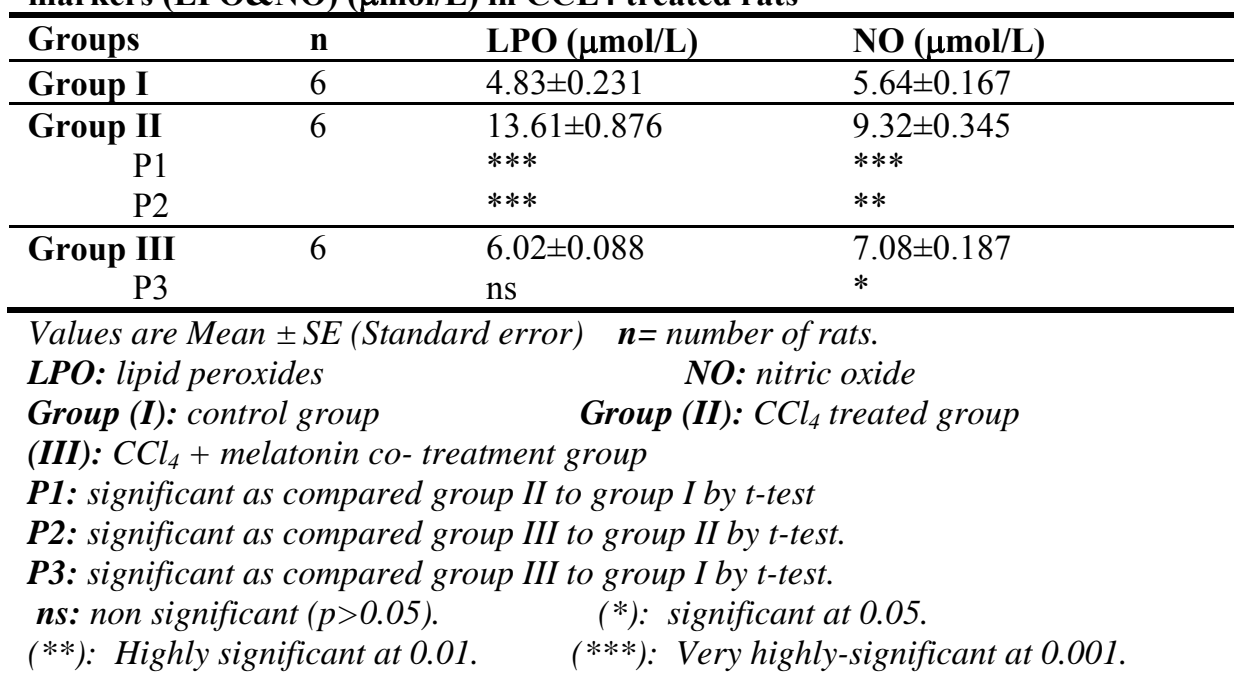


Table (2): Effect of melatonin co-treatment on serum levels of antioxidant enzymes (GSH-Px \&SOD) $(\mu \mathrm{mol} / \mathrm{L})$ in $\mathrm{CCl}_{4}$ treated rats

\begin{tabular}{llll}
\hline Groups & N & GSH-Px & S.O.D \\
\hline Group I & 6 & $4.26 \pm 0.189$ & $5.82 \pm 0.207$ \\
\hline Group II & 6 & $1.72 \pm 0.089$ & $1.13 \pm 0.065$ \\
P1 & & $* * *$ & $* * *$ \\
P2 & & $* * *$ & $* * *$ \\
\hline Group III & 6 & $4.06 \pm 0.207$ & $4.32 \pm 0.199$ \\
P3 & & ns & $*$ \\
\hline
\end{tabular}

Values are Mean \pm SE (Standard error) GSH-Px: Glutathione peroxidase Group (I): control group $n=$ number of rats.

(III): CCL4 + melatonin co- treatment group

P1: significant as compared group II to group I by t-test

P2: significant as compared group III to group II by t-test.

P3: significant as compared group III to group I by t-test.

ns: non significant $(p>0.05)$.

(*): significant at 0.05 .

(***): Very highly-significant at 0.001

Table (3): Effect of melatonin co-treatment on serum levels of liver enzymes $(\mathrm{ALT} \& \mathrm{AST})(\mathrm{U} / \mathrm{L})$ in $\mathrm{CCl}_{4}$ treated rats

\begin{tabular}{rlll}
\hline Groups & n & ALT & AST \\
\hline Group I & 6 & $37.38 \pm 2.351$ & $5.60 \pm 0.476$ \\
\hline Group II & 6 & $157.97 \pm 0.345$ & $7.83 \pm 0.307$ \\
P1 & & $* * *$ & $* * *$ \\
P2 & & $* * *$ & $* * *$ \\
\hline Group III & 6 & $61.34 \pm 4.155$ & $6.42 \pm 0.215$ \\
P3 & & $*$ & $*$ \\
\hline
\end{tabular}

Values are Mean \pm SE (Standard error) $\quad \boldsymbol{n}=$ number of rats.

ALT: alanin aminotransferase

AST: asprtate aminotransferase

Group (I): control group

Group (II): CCL4 treated group

(III): $\mathrm{CCL}_{4}+$ melatonin co- treatment group

P1: significant as compared group II to group I by t-test

P2: significant as compared group II to group III by t-test.

P3: significant as compared group III to group I by t-test.

$(*)$ significant at 0.05 .

(***): Very highly-significant at 0.001 .

Table (4): Correlation between hyaluronic acid and liver enzymes (ALT\&AST)

\begin{tabular}{ccc}
\hline Variables & \multicolumn{2}{l}{ Hyaluronic acid } \\
\cline { 2 - 3 } & $\mathbf{r}$ & $\mathbf{P}$ \\
\hline ALT & 0.973 & $0.001^{* * *}$ \\
\hline AST & 0.975 & $0.001^{* * *}$ \\
\hline
\end{tabular}

(***): Very highly-significant at 0.001 (by Sperman correlation test).

ALT: alanin aminotransferase $\quad$ AST: asprtate aminotransferase 


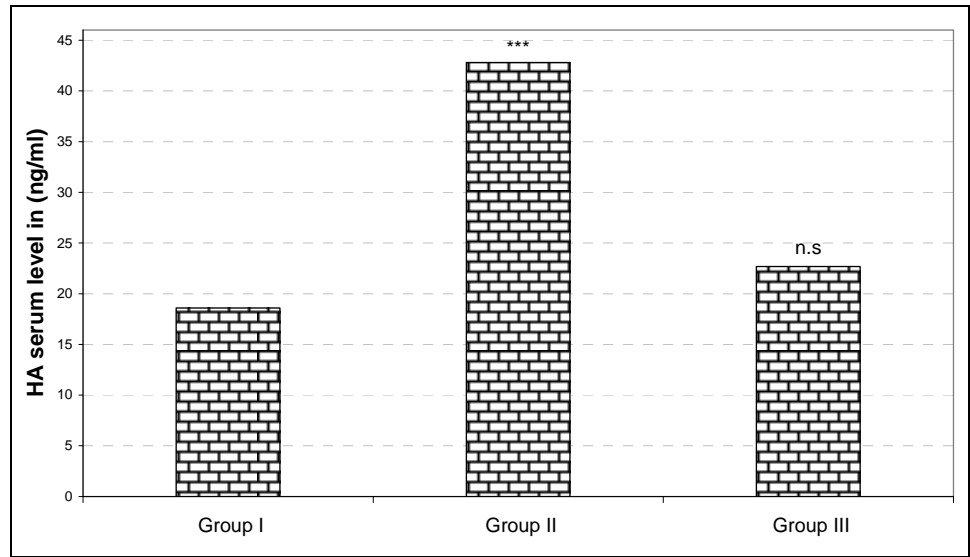

Graph (1): Serum Hyaluronic acid ( $\mathrm{ng} / \mathrm{ml}$ ) of the studied groups

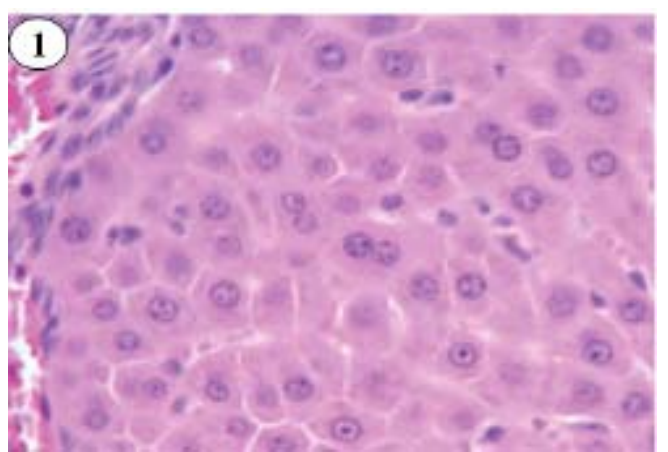

Figure (1): Light microscopic picture of liver tissue from rat of group (I) showing normal histological picture of control rat (H\&E x 400).

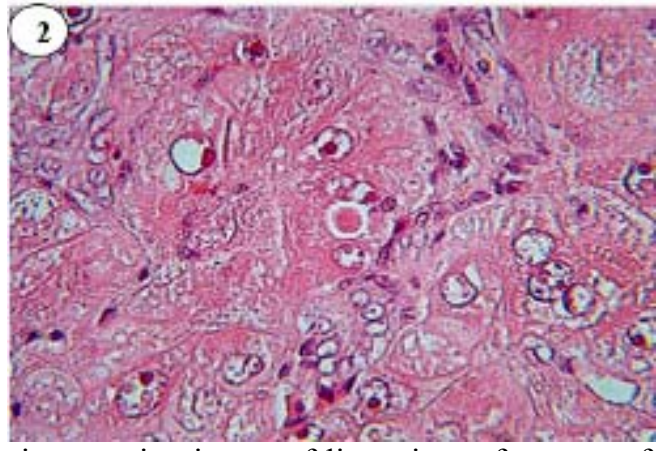

Figure (2): Light microscopic picture of liver tissue from rat of group (II) showing histopathological changes induced by $\mathrm{CCl}_{4}$ injection (H\&E x 400). 


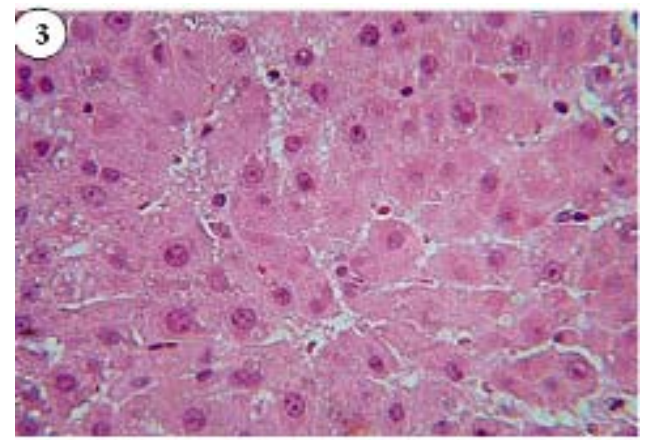

Figure (3): Light microscopic picture of liver tissue from rat of group (III) showing effect of melatonin on histopathological liver injury induced by $\mathrm{CCl}_{4}(\mathrm{H} \& \mathrm{E}$ x 400$)$

\section{DISCUSSION}

Hepatic fibrosis is a progressive pathological process involving multiple cellular and molecular events that lead ultimately to the accumulation of collagen and extra cellular matrix proteins in the space of Disse. Chronic injury leading to fibrosis in the liver occurs in response to a variety of insults, including viral infection, tissue-immune mediated damage, toxic agents, obstructive jaundice, gene abnormalities, or alcohol and nonalcohol steatohepatitis. When this injury process is combined with ineffective regeneration and repair, there is increasing distortion of the normal liver architecture, and the end result is cirrhosis ${ }^{(34,35)}$. Current evidence indicates that hepatic fibrosis even cirrhosis is dynamic and can be bidirectional (involving phases of progression and regression) ${ }^{(36)}$. The induction of oxidative stress is a key feature in the destruction of parenchyma and the activation of stellate cells that leads to liver cirrhosis and fibrosis ${ }^{(37)}$.
$\mathrm{CCl}_{4}$ is commonly used for inducing liver fibrosis in experimental animals. It has been reported that $\mathrm{CCl}_{4}$ damages liver mitochondria by inhibition of cytochrome oxidase and by enhanced oxidative stress. Lipid peroxidation is considered to be the most important mechanism in the pathogenesis of liver damage induced by $\mathrm{CCl}_{4}{ }^{(38)}$. One mechanism of the tissue-damaging effects of $\mathrm{CCl}_{4}$ is considered to include the generation of trichloromethyl $\left(\mathrm{CCl}_{3}\right)$ and trichloromethylperoxyl $\quad\left(\mathrm{CCl}_{3} \mathrm{O}_{2}\right)$ radicals and covalent binding of $\mathrm{CCl}_{3}$ to membrane proteins and lipids. These radicals can accept protons from unsaturated fatty acid molecules of membrane lipids resulting in the initiation of LPO processes and loss of membrane enzymes ${ }^{(11)}$.

Melatonin has been reported to reduce damage to hepatic tissues after $\mathrm{CCl}_{4}$ intoxication ${ }^{(39)}$. In many studies, hepatic fibrosis was successfully induced by subcutaneous injection of sterile $\mathrm{CCl}_{4}$. Through this hepatic fibrosis model, the effects of melatonin on hepatic fibrosis induced by $\mathrm{CCl}_{4}$ in rats were examined ${ }^{(7)}$. 
In the present study, subcutaneous injection of rats of group II with $\mathrm{CCl}_{4}(2 \mathrm{ml} / \mathrm{kg}$ of body weight, twice a week for 8 weeks) resulted in a significant increase in serum level of oxidative stress markers as indicated by increased serum level of lipid peroxides (LPO) and nitric oxide (NO). This was consistent with the findings of other investigators $\mathbf{( 1 4 , 4 0 , 4 1 , 1 9 )}$. In 2002, Drewa et al. ${ }^{(37)}$ reported an increase in serum level of malondialdehyde (MDA), the main product of lipid peroxidation and its concentration is generally presented as the total level of lipid peroxidation products. As an end product of lipid peroxidation, MDA can produce ozone, which reacts rapidly with cellular structures, generates hydrogen peroxide and other reactive oxygen species, leading to peroxidation and denaturation of membranes ${ }^{(42)}$. Also, significant increases in NO serum level have been observed in group II as compared to that of its control values. This was in agreement with the finding of other investigators ${ }^{(11)}$, who recorded that inflammatory processes in the liver after $\mathrm{CCl}_{4}$ injection may be responsible for the increase in NO level in the rat liver and blood. In the present study, the increase of plasma levels of lipid peroxides and nitric oxide might be attributed to oxidative stress induced by $\mathrm{CCl}_{4}$ injection. Additionally, $\mathrm{CCl}_{4}$ administration to rats of group II induced significant reduction in serum levels of antioxidant enzymes as indicated by significant decrease in serum levels of glutathione peroxidase (GSH-Px) and superoxide dismutase (SOD) in all animals of that group as compared to that of its control values. This was in agreement with the finding of $\mathbf{W u}$ et al.(2007) and Wang et al. $(2007)^{(\mathbf{1 9 , 4 1 )}}$ which indicate that $\mathrm{CCl}_{4}$ had disrupted the antioxidant defense mechanisms causing oxidative damage of hepatic cells.

A number of antioxidants have been tested in experimental liver fibrosis models in attempts to limit the oxidative damage ${ }^{\text {(22). }}$. In the current study administration of melatonin (20 $\mathrm{mg} / \mathrm{kg}$ twice a week for 8 weeks from the beginning of $\mathrm{CCl}_{4}$ injection) to rats of group III $\left(\mathrm{CCl}_{4}+\right.$ Melatonin group) induced significant reduction of mean serum levels of LPO and NO levels. Additionally, significant increase in mean serum levels of both GSH-Px and SOD has been revealed in comparison with group II. These findings indicate that melatonin cotreatment with $\mathrm{CCl}_{4}$ could decrease lipid peroxidation and free radical formation and lead to a substantial recovery of the major antioxidant enzymes, thus limiting oxidative damage to the liver and could be considered as a protective agent against liver injury. These results were in agreement with previous studies which recorded significant reduction of oxidative stress markers with marked increase in antioxidant levels after melatonin treatment in cases of hepatic intoxication ${ }^{(22,43)}$. In 2004, Tahan et al. ${ }^{(44)}$ found that melatonin can restore GSH-Px activity in a rat liver fibrosis model. Hepatic GSH is known to play an important role in protecting livers against injury in rats treated with $\mathrm{CCl}_{4}{ }^{(45)}$. Also, melatonin administration prevented $\mathrm{CCl}_{4}{ }^{-}$ induced NO generation. This may be due to the scavenging of $\mathrm{NO}$ by 
melatonin and the ability of this indole to inhibit nitric oxide synthase ${ }^{(46)}$.

The mechanisms of the regulatory and protective effects of melatonin have been extensively studied in recent years. The beneficial properties of melatonin include its amphiphilicity and limited toxicity even at high pharmacological concentrations ${ }^{(47,18)}$. Melatonin protects DNA, proteins, and biological membrane lipids from the deleterious effects of free radicals, without the need for a specific receptor on the cells ${ }^{(48)}$.

In general, melatonin has properties of both a direct and indirect antioxidant agent. In 2000, Liu et al. ${ }^{(49)}$ reported that melatonin is not only a direct antioxidant but also an indirect antioxidant through enhancement of antioxidant enzyme activities in liver. Although the activity of melatonin is in part related to its direct antioxidant effect (through direct scavenger of free radicals), there are several studies suggesting that its activity might be associated with an indirect antioxidant activity by influencing gene expression and regulation of antioxidant enzymes $(\mathbf{5 0 , 5 1 )}$.

Melatonin also has been reported to stimulate the activities of enzymes and increase gene expression that improves the total antioxidative defense capacity of the organism, i.e., SOD, glutathione peroxidase, and glutathione reductase ${ }^{(\mathbf{5 2 , 5 3 , 5 4 )}}$. Moreover, recent studies indicate that melatonin is effective in inhibiting oxidative liver damage. This effect may be due to the positive transcriptional activation of melatonin in several antioxidant-related genes $^{(54)}$.

The protective actions of melatonin may be due to the molecule itself and to its metabolites. The efficacy of melatonin in reducing oxidative stress is increased by the metabolites that produces while scavenging, i.e. cyclic 3-hydroxymelatonin (cyclic 3-OHM), N-acetylN2-formyl-5-methoxykuramine

(AFMK), and -N1-acetyl-5methoxykuramine (AFM), which also appear to be efficient scavengers. Thus, second and third generation metabolites of melatonin may well contribute to the ability of the parent molecule to protect against oxidative stress. Because of this melatonin, rather than scavenging a single radical, may neutralize a number of toxic reactions via an antioxidant cascade $^{(55,56)}$.

Different antioxidants have been tested in experimental liver fibrosis models to decrease oxidative damage. In a comparative study between the antioxidant protective effect of both melatonin and vitamin E, carried out by Montilla et al. ${ }^{(26)}$, they found that melatonin (at a much lower dose than vitamin E) was much more efficient than vitamin $\mathrm{E}$ in reducing the negative parameters of oxidative stress and provided a significantly greater hepatoprotective effect against the liver injury than did a much higher dose of vitamin E. Also, melatonin had a more potent effect in restoring antioxidative enzyme activities. They added that melatonin is an effective antioxidant and a free radical scavenger as it can cross biological membranes easily and reach all compartments within the cell due to 
its small size and high lipophilicity. Also, Rozov et al. ${ }^{(57)}$ recorded that melatonin has a higher antioxidant efficiency than vitamin E and GSH, which are known as powerful antioxidants.

In the present study, hepatic damage induced by $\mathrm{CCl}_{4}$ administration was evaluated by measuring serum level of some of hepatic enzymes as alanine amino transferase (ALT) and aspartate aminotransferase (AST). Rats of $\mathrm{CCl}_{4}$ treated group (group II) showed significant increase of ALT and AST levels as compared to values of control group. After melatonin cotreatment to group III, a significant decrease of these hepatic enzymes was observed in all treated animals, which indicates that melatonin has a protective effect on hepatic cells after $\mathrm{CCl}_{4}$ intoxication. These findings were in agreement with other investigators, who recorded marked improvement of hepatic functions with reduction of hepatic enzymes by administration of melatonin to animals with $\mathrm{CCl}_{4}$ hepatic intoxication ${ }^{(\mathbf{1 2 , 5 8 , 5 9})}$. In 2008, Ogeturk et al. ${ }^{(60)}$ revealed that liver dysfunction after $\mathrm{CCl}_{4}$ intoxication caused marked increases in plasma ALT and AST activities. Also, Rasha et al. (2009) ${ }^{(\mathbf{1 0})}$ reported that a single dose of $\mathrm{CCl}_{4}$ induced hepatotoxicity manifested biochemically by significant elevation of activities of liver enzymes, such as ALT and AST. They added that there was marked reduction of hepatic enzyme activities after melatonin administration. In 2009, Hong et al. ${ }^{(7)}$ proved that melatonin administration to $\mathrm{CCl}_{4}$ treated rats (at a dose of $10 \mathrm{mg} / \mathrm{kg}$ ) was effective in reducing serum ALT and AST levels, indicating that melatonin can protect liver and alleviate the progression of hepatic fibrosis.

In the current study, the fibrotic effect of $\mathrm{CCl}_{4}$ on hepatic tissues of group II rats was assessed by measuring serum level of hyaluronic acid (HA). It is well known that HA is a good serum marker of hepatic fibrogenesis even at its early stage $(61,14)$. So, it is considered a good marker for detection of initial phase of hepatic fibrosis which help in early diagnosis of hepatic fibrogenesis and able to assess severity of liver disease as mentioned by Kopk-Aguiar et al. $(2002)^{(62)}$.

The result of the present study showed significant increase in serum level of $\mathrm{HA}$ in $\mathrm{CCl}_{4}$ treated group (group II) when compared to control group (group I). This increase in HA in the present study was in agreement with that of Mchutchison et al. $(2000)^{(63)}$ who stated that there was an increase in serum levels of HA in patients with early phase of hepatic injury before developing of fibrosis or cirrhosis. Additionally, the current study revealed a significant positive correlation between serum levels of HA and hepatic enzymes (ALT\&AST). These data were in agreement with the result of Xie et al. $(2003)^{(64)}$ as they recorded that the concentrations of serum HA was positively correlated with the inflammatory activity and degrees of hepatic fibrosis and cirrhosis. Lu et al. (2003) ${ }^{(\mathbf{6 5})}$ stated that serum HA was correlated with the degree of hepatic inflammation and liver fibrosis stage and correlated with other liver function parameters 
including AST, ALT, albumin, A/G ratio and alkaline phosphatase (ALP).

This increase in serum level of $\mathrm{HA}$ in group II, 8 weeks after $\mathrm{CCl}_{4}$ treatment could be explained by modulation of uptake and degradation of serum HA by the hepatic endothelial cells in this early reversible stage of hepatic fibrosis ${ }^{(66)}$. Also, Patel et al. $(2003)^{(67)}$ stated that in patients with fibrosis, the elevation of serum HA is believed to be the result of increased synthesis by activated stellate cells and decreased clearance by sinusoidal endothelial cells. Additionally, Abd-el-Fattah et al. $(2006)^{(68)}$ explained that HA increases due to diminishing $\mathrm{HA}$ clearance by the cirrhotic liver cells and also hyaluronidase enzyme activity decreased proportionally to the severity of liver disorders.

The present study demonstrates partial protective effect of melatonin on hepatic fibrosis induced by $\mathrm{CCl}_{4}$. Co-treatment of rats of group III with melatonin (at the dose of $20 \mathrm{mg} / \mathrm{kg}$ twice a week for 8 weeks), significantly reduced serum levels of $\mathrm{HA}$ as compared with the rats that received only $\mathrm{CCl}_{4}$ (group II). This was in agreement with many previous studied who proved that melatonin could decrease hepatic fibrosis and serum HA levels in rats with hepatic injury caused by $\mathrm{CCl}_{4}{ }^{(63,65,7)}$. In 2009 , Hong et al. ${ }^{(7)}$ recorded that; treatment with melatonin $(10 \mathrm{mg} / \mathrm{kg})$ could significantly reduce serum levels of HA. The decrease of serum HA level indicates that melatonin can inhibit collagen deposition in liver.

Previous reports have shown that the synthesis or metabolism of collagen is closely associated with melatonin. It was shown that melatonin has an inhibitory role on collagen accumulation with suppressing the pinealectomy-induced elevation of collagen content during wound healing ${ }^{(69)}$. Other evidence suggested a relationship between primary biliary cirrhosis and melatonin deficiency because of the demonstration of increased pigmentation and accelerated fibrosis in pinealectomized rats ${ }^{(70)}$. Also, in 2002, Arslan et al. ${ }^{\text {(71) }}$ proved that melatonin has therapeutic activities in bleomycin-induced pulmonary fibrosis

An increase of oxidative stress markers production can play an important role in the formation of hepatic fibrosis via increasing stellate cell activation and collagen synthesis. It has been shown that MDA can activate stellate cells that produce collagen. Several lines of evidence suggest that melatonin plays an important role in regulation of collagen levels and inhibition of collagen accumulation ${ }^{(72)}$. The results of the present study revealed that treatment with melatonin could significantly block increased LPO, suggesting that melatonin decreases oxidative stress via decreasing lipid peroxidation, so it can play an antifibrotic role in hepatic fibrosis induced by $\mathrm{CCl}_{4}$ in rats. In 2005 , Wang et al. ${ }^{(58)}$ proved that melatonin has an effective protective role against hepatic damage in a rat hepatic fibrosis model induced by a 6 -weeks $\mathrm{CCl}_{4}$ regimen. This protective action of melatonin might be related to its antioxidant activity and inhibition of proinflammatory cytokines production. 
In 2006 Sigala et al. ${ }^{(73)}$ showed that products of lipid peroxidation can stimulate collagen gene expression in cultured fibroblasts and they proposed that lipid peroxidation could be a link between tissue injury and tissue fibrogensin. From all the above studies, it can be speculated that early inhibition of lipid peroxidation by using a proper antioxidant as melatonin may be the most important mechanism of reducing liver fibrosis.

In the present study, liver injury was assessed with biochemical and histological parameters. Histopathological examination of liver specimens in the $\mathrm{CCl}_{4}$ treated rats (group II) showed that the liver structure was disrupted with dilated blood vessels, collagen deposition and more necrotic and fatty degenerated liver cells compared with the controls (figure 2). In group III $\left(\mathrm{CCl}_{4}+\right.$ melatonin), histological study of hepatic tissues showed that melatonin could obviously attenuate the extent of necrosis and reduce the histological signs of liver damage and fibrosis (figure 3), documenting a significant protective effect of melatonin against liver damage and fibrosis caused by $\mathrm{CCl}_{4}$ injection. These findings are consistent with previously reported results $^{(7,59,76,77)}$. In 2005, Wang et al. ${ }^{(58)}$ proved that melatonin at the dose of 10 or $20 \mathrm{mg} / \mathrm{kg}$ significantly reduced the scores of liver fibrosis, documenting a significant protective effect of melatonin on hepatic histology and inhibition of collagen deposition caused by hepatic intoxication. Additionally, in 2005, Zavodnik et al., ${ }^{(59)}$ stated that exposure to $\mathrm{CCl}_{4}$ induced substantial morphological changes in rat liver with disruptions of hepatic structure including necrosis and fatty and hydropic dystrophy. Melatonin administration lowered the degree of necrosis and dystrophic changes in these rats. Also, in 2009, results of the study carried by Hong et al. $^{(7)}$ suggested that melatonin could decrease the scores of hepatic fibrosis and serum ALT and AST levels in rats with hepatic injury caused by $\mathrm{CCl}_{4}$.

The present study revealed the hepatic protective effect of melatonin administration in case of $\mathrm{CCl}_{4}$-hepatic toxicity. The study also explained different mechanisms of this protective effect of melatonin mainly through decreasing oxidative stress and restoring antioxidative enzymes as well as its anti-fibrotic effect. Another mechanism of melatonin hepatic protective effect may be due to its antiapoptotic effect as stated by Guha et al., in $2007^{(78)}$, but the exact mechanism of melatonin-provided prevention of hepatic apoptosis is not completely clear. Some investigators (Noyan et al., 2006 and Molpeceres et al., 2007) ${ }^{(18,79)}$ attributed the antiapoptotic effects of melatonin to its antioxidant and free radical scavenging activities. In 2008, Ogeturk et al., ${ }^{(60)}$ found that chronic administration of $\mathrm{CCl}_{4}$ induced apoptosis in the liver. Furthermore, they showed that melatonin substantially reduced $\mathrm{CCl}_{4}$-induced apoptotic changes in rats. This antiapoptotic effect of melatonin was in agreement with other studies showing that melatonin diminishes apoptosis in endotoxemic intestinal injury (Ozdemir et al., 2007) ${ }^{(\mathbf{8 0})}$ and in formaldehyde-induced cortical 
neurotoxicity (Zararsiz et al., 2007) ${ }^{(81)}$.

Andrabi et al. (2004) ${ }^{(82)}$ and Guha et al. (2007) ${ }^{(77)}$, showed that melatonin exerts its antiapoptotic action via direct inhibition of the mitochondrial permeability transition pore. In 2005, Esrefoglu et al. ${ }^{(83)}$ stated that melatonin significantly reduces cell death in tissues from both the necrotic and apoptotic pathways. Meki et al. $2001^{\mathbf{( 8 4 )}}$ showed that in a rat liver injury caused by aflatoxin B1 (a toxin which leads to apoptosis) melatonin treatment of the rats reduced the apoptotic and necrobiotic changes in the liver. Additionally, Jou et al. (2004) ${ }^{(\mathbf{8 5})}$ showed that melatonin, readily rescued mitochondria from oxidative stressinduced dysfunction and effectively prevented subsequent apoptotic events and death in rat brain astrocytes. So, it seems that melatonin reinforces its therapeutic potential to combat a variety of oxidative stress-induced mitochondrial dysfunctions as well as mitochondria-mediated apoptosis in various diseases.

In conclusion, our study shows that melatonin, which is a safe molecule without relevant noxious side effects, has a substantial hepatoprotective effect in a rat hepatic fibrosis model induced by a 8 -weeks' $\mathrm{CCl}_{4}$ regimen. The results of the biochemical and histological measurements reported in this study proved that co-administration of melatonin with $\mathrm{CCl}_{4}$ was able to decreases oxidative stress, hepatic cell damage and liver fibrosis in rat liver during hepatic intoxication with $\mathrm{CCl}_{4}$. The protective effect of melatonin may be due to both its direct radical scavenging properties and indirect effects as a regulator of antioxidant systems. Therefore, the study proposes that melatonin may be a valuable drug for inhibition of unwanted fibrosis in patients exposed to different hepatotoxic agents.

\section{Acknowledgments}

The authors of this study thank Dr. Hemmat Hariedy, (Assistant Professor of Histology, Faculty of Medicine, Assuit University) for her excellent histological assistance and her kindly help.

\section{REFERENCES}

1- Nooman Z, Khalil M, Nafeh M, Elwan I, el-Sharkawi M, Omar M, Atta M, Reda I. (1978): Behavior of hepatitis B antigen in bilharzial patients infected with HBs positive viral hepatitis. Egypt J Bilharz., 4(1):79-87.

2- Svegliati G, Saccomanno $S$ and Van Goor H. (2001): Involvement of reactive oxygen species and nitric oxide radical in activation and proliferation of rat hepatic stellate cells. Liver 21:112.

3- Cruz A, Padillo J, Torres E. (2005): Melatonin prevents experimental liver cirrhosis induced by thioacetamide in rats. J. Pineal Res., 39:143-150.

1. 4-Loguercio $C$, Federico $A$. (2003): Oxidative stress in viral and alcoholic hepatitis. Free Radic Biol Med., 34:1-10.

4- Koruk M, Aksoy H, Akcay F. (2002): Antioxidant capacity and nitric oxide in patients with hepatic cirrhosis. Ann Clin Lab Sci., 32:252-256. 
5- Poynard T, Mchutchison J, Manns M. (2002): Impact of Pegylated interferon Alfa-2b and ribavirin on liver fibrosis in patients with chronic hepatitis $\mathrm{C}$. Gastroenterology 122:13031313.

6- Hong R. T, Jian-Ming $X$, and Mei Q. (2009): Melatonin ameliorates experimental hepatic fibrosis induced by carbon tetrachloride in rats. World $\mathrm{J}$ Gastroenterol., 15(12): 14521458.

7- Agency for Toxic Substances and Disease Registry (ATSDR) (2005): Toxicological profile for carbon tetrachloride. US Department of Health and Human Services, Public Health Service, Atlanta, GA, pp. 2-4.

8- Hartely P, Kolaja L, Reichard J. (1999): 4-Hydroxynonenal and malondialdehyde hepatic protein adducts in rats treated with carbon tetrachloride: immunochemical detection and lobular localization. Toxicol Appl Pharmacol.,161:23-33.

9- Rasha S. A. Ismail, A. A, Aly R. (2009): Carbon tetrachlorideinduced liver disease in rats: the potential effect of supplement oils with vitamins $\mathrm{E}$ and $\mathrm{C}$ on the nutritional status. GMS German Medical Science. 7, ISSN 16123174.

10- Recknagel O, Glende A, Dolak A, Waller L. (1989): Mechanisms of carbon tetrachloride toxicity. Pharmacol Ther., 43: 139-154.

11- Deulofeu R, Pares A, Rubio M. (2000): S-adenosylmethionine prevents hepatic tocopherol depletion in carbon tetrachlorideinjured rats. Clin Sci., 99:315320.

12- Bruck R, Shirin H, Aeed $H$. (2001): Prevention of hepatic cirrhosis in rats by hydroxyl radicals scavengers. J Hepatol., 35:457-464.

13- Al-Shabanah, Alam O, Nagi K, Al-Rikabi M. (2000): Protective effect of aminoguanidine, a nitric oxide synthase inhibitor, against carbon tetrachloride induced hepatotoxicity in mice. Life Sci., 66: 265-270.

14- Teocharis E, Margeli $P$, Skaltsas D, Spiliopoulou A, Koutselinis S. (2001): Induction of metallothionein in the liver of carbon tetrachloride intoxicated rats: an immunohistochemical study. Toxicology 161: 129-138.

15- Kus I, Ogeturk M, Oner H, Sahin S, Yekeler H, Sarsilmaz M. (2005): Protective effects of melatonin against carbon tetrachloride-induced

hepatotoxicity in rats: a light microscopic and biochemical study. Cell Biochem Funct., 23: 169-174.

16- Sun F, Hamagawa E, Tsutsui C, Ono Y. (2001): Evaluation of oxidative stress during apoptosis and necrosis caused by carbon tetrachloride in rat liver. Biochim Biophys Acta 1535: 186-191.

17- Noyan T, Komuroglu U, Bayram I, Sekeroglu M. (2006): Comparison of the effects of melatonin and pentoxifylline on carbon tetrachloride-induced liver toxicity in mice. Cell Biol Toxicol., 22: 381-391. 
18- Wu Y, Li L, Wen T, Li Q. (2007): Protective effects of echinacoside on carbon tetrachloride-induced hepatotoxicity in rats. Toxicology 232: 50-56.

19- Parola M, Robino G. (2001): Oxidative stress-related molecules and liver fibrosis. J Hepatol., 35: 297-306.

20- Shimizu I. (2001): Antifibrogenic therapies in chronic HCV infection. Curr Drug Targets Infect Disord. 1: 227-240.

21- Cruz A, Padillo J, Granados J, Tunez I, Munoz C, Briceno J. (2003): Effect of melatonin on cholestatic oxidative stress under constant light exposure. Cell Biochem Funct; 21: 377-380.

22- Allegra $M$, Reiter J, Tan $X$. (2003): The chemistry of melatonin's interaction with reactive species. J Pineal Res., 34:1-10.

23- Chen C, Ng J, Chiu T. (2003): Altered neutrophil apoptosis activity is reversed by melatonin in liver ischemia-reperfusion. $\mathrm{J}$ Pineal Res., 34:260-264.

24- Bruck R, Aeed H, Avni Y. (2004): Melatonin inhibits nuclear factor kappa B activation and oxidative stress and protects against thioacetamide induced liver damage in rats. J Hepatol., 40:86-93.

25- Montilla P, Cruz A, Padillo J, Tunez I, Gascon F, Munoz C, Gomez M, Pera C. (2001): Melatonin versus vitamin $\mathrm{E}$ as protective treatment against oxidative stress after extra- hepatic bile duct ligation in rats. J Pineal Res., 31: 138-144.

26- Guechot J, Serfaty $L$ and Bonnand M. (2000): Prognostic value of serum hyaluronan in patients with compensated $\mathrm{HCV}$ cirrhosis. J. Hepatol., 32:447-452.

27- Thayer S. (1985): Serum lipid peroxides in rats treated chronically with adriamycine. Biochem. Pharmacol., 33 (14): 2259-2263.

28- Van Bezooijen L, Que I, Ederveen G, Klousterboer J and Lovik W. (1998): Plasma nitrate and nitrite level are regulated by ovarian steroids but do not correlate with trabecular bone mineral density in rats. J. Endocrinology 159: 27-34.

29- Ellman L. (1959): Tissue sulfhydryl groups. Archives Biochem.. Biophys., 82: 70-77.

30- Misra $H$. and Fridovich $I$. (1972): The role of superoxide anion in the auto-oxidation of epinephrine and a simple assay for superoxide dismutase. J. Biol. Chem., 215: 3170 - 3175.

31- Breuer J. (1996): Report on the symposium "Drug effects in clinical chemistry method" Eur. J. Cin. Chem. Clin. Biochem., 34: 385-386.

32- Drury R. and Wallington $A$. (1980): Carleton`s histological technique ,Oxford University Press,New York $5^{\text {th }}$ edition.

33- Safadi R., Friedman L. (2002): Hepatic fibrosis - role of hepatic stellate cell activation. Medscape General Medicine 4 (3): 27.

34- Friedman L. (2003): Liver fibrosis - from bench to bedside. 
Journal of Hepatology 38 (Suppl 1), S38-S53.

35- Pinzani M., Rombouts K. ( 2004): Liver fibrosis: from the bench to clinical targets. Digestive and Liver Disease 36 (8): 231-242.

36- Drewa G, Malinowska E, Woźniak A, Drozd F, Mila C, Rozwodowska M, Kowaliszyn B, Czajkowski R. (2002): Activity of superoxide dismutase and catalase and the level of lipid peroxidation products reactive with TBA in patients with psoriasis. Med Sci Monit., 8: 338343.

37- Demirdag $K$, Bahcecioglu $H$, Ozercan H, Ozden M, Yilmaz S, Kalkan A (2004): Role of Lcarnitine in the prevention of acute liver damage induced by carbon tetrachloride in rats. $\mathrm{J}$ Gastroenterol Hepatol., 19: 333338.

38- Ohta Y, Kongo M, Nishida K, Ishiguro I. (2000): Therapeutic effect of melatonin on carbon tetrachloride-induced acute liver injury in rats. J Pineal Res., 28: 119-126.

39- Mansour A. (2000): Protective effects of thymoquinone and desferrioxamine against hepatotoxicity of carbon tetrachloride in mice. Life Sci., 66: 2583-2591.

40- Wang Y, Ma L, Liu T, Tian W, Fu H. (2007): Protective effect of salvianic acid a on acute liver injury induced by carbon tetrachloride in rats. Biol Pharm Bull., 30: 44-47.

41- Ajamieh H. Menéndez S, Mar G, Jalil E, Re L, Giuliani A,
Fern OS. (2004): Effects of ozone oxidative preconditioning on nitric oxide generation and cellular redox balance in a rat model of hepatic ischemiareperfusion. Liver Int; 24: 55-62.

42- Bülbüller N, Akku A, Cetinkaya Z, Ilhan S, Krkl C, Dogru O. (2002): Effects of melatonin and lactulose on the liver and kidneys in rats with obstructive jaundice. Pediatr Surg Int., 18: 677-68.

43- Tahan V, Ozaras R, Canbakan B, Uzun H, Aydin S, Yildirim B, Aytekin H, Ozbay G, Mert A, Senturk H. (2004): Melatonin reduces dimethylnitrosamine-induced liver fibrosis in rats. J Pineal Res., 37: 78-84.

44- Li CH, Pan LH, Yang ZW, Li CY, Xu WX. (2008): Preventive effect of Qianggan-Rongxian Decoction on rat liver fibrosis. World J Gastroenterol., 14: 35693573.

45- Reiter J, Tan X, Sainz M, Lopez S. (2002): Melatonin: reducing the toxicity and increasing the efficacy of drugs. J Pharm Pharmacol., 54: 12991321.

46- Jan E, Hamilton D, Seward N, Fast K, Freeman D, Laudon $M$. (2000): Clinical trials of controlled-released melatonin in children with sleep-wake cycle disorders. J Pineal Res., 29: 34 39.

47- Reiter J. (1998): Oxidative damage in the central nervous system: Protection by melatonin. Prog. Neurobiol., 56:359- 384. 
48- Liu F, Ng B. (2000): Effect of pineal indoles on activities of th antioxidant defense enzymes superoxide dismutase, catalase, and glutathione reductase, and levels of reduced and oxidized glutathione in rat tissues. Biochem Cell Biol., 78: 447-453.

49- Steinhiber, D., M. Brings, O. Werz, I. Wiesenberg, Danielsson, J.P. Kahlen, S. Nayeri, M. Scharader, C. Calbrtg (1995): The nuclear receptor of melatonin represses 5lipoxygenase gene expression in human B lymphocytes. J. Biol. Chem., 270:7037-7040.

50- Reiter J., L. Tang J. Garcia A. Mun OZ-H. (1997): Pharmacological actions of melatonin in free radical pathophysiology. Life Sci., 60:2255-2272.

51- Reiter J, Tan X, Osuna C, Gitto E. (2000): Actions of melatonin in the reduction of oxidative stress. J. Biomed.l Science 7 (3), 444-458.

52- Kilanczyk E, Bryszewska M. (2003): The effect of melatonin on antioxidant enzymes in human diabetic skin fibroblasts. Cellular and Molecular Biology Letters 8 (2), 333-336.

53- Rodriguez C., Mayo C., Sainz M., Antolin, I., Herrera F., Reiter, R.J. (2004): Regulation of antioxidant enzymes: a significant role for melatonin. J. Pineal Research 36 (1), 1-9.

54- Silva O, Rodrigues R, Carvalho Rl. (2004): Oxidation of melatonin and its catabolites, N1acetyl-N2-formyl-5-

methoxykynuramine and N1- acetyl-5-methoxykynuramine, by activated leucocytes. J Pineal Res., 37:171-177.

55- Onuki J, Almeida A, Medeiros G, Mascio D. (2005): Inhibition of 5-aminolevulinic acid-induced DNA damage by melatonin, N1acetyl-N2-formyl-5-

methoxykynuramine, quercetin or resveratrol. J Pineal Res., 38:107116.

56- Rozov V, Filatova V, Orlov A, Volkova V, Zhloba R, Blashko L, Pozdeyev N. (2003): N1acetyl-N2-formyl-5-

methoxykynuramine is a product of melatonin oxidation in rats. $\mathrm{J}$ Pineal Res., 35: 245-250.

57- Wang H, Wei T, Wang NP, Gui SY, Li Wu, Wu-Yi S. (2005): Melatonin ameliorates carbon tetrachloride-induced hepatic fibrogenesis in rats via inhibition of oxidative stress. Life Sciences 77:1902-1915.

58- Zavodnik1 L, Zavodnik B, Lapshina1 E, Belonovskaya1 B, Martinchik1 R, Reiter J. (2005): Protective effects of melatonin against carbon tetrachloride hepatotoxicity in rats. Cell Biochem Funct., 23: 353-359.

59- Ogeturk M, Kus 1, Pekmez H, Yekeler H, Sahin S, Sarsilmaz Y. (2008): Inhibition of carbon tetrachloride-mediated apoptosis and oxidative stress by melatonin in experimental liver fibrosis Toxicology and Industrial Health 24: 201-208.

60- Kaneda H, Hashimoto E, Yatsuji S, Tokushige K, Shiratori K. (2006): Hyaluronic acid levels can predict severe 
fibrosis and platelet counts can predict cirrhosis in patients with nonalcoholic fatty liver disease. $\mathrm{J}$ Gastroenterol Hepatol., 21: 14591465.

61- Kopke-Aguiar A, Martins $M$ and Passerott C. (2002): Serum hyaluronic acid as a comprehensive marker to assess severity of liver disease in schistosomiasis. Acta Tropic., 84 (2): 117-126.

62- Mchutchison G, Blatt M, Medina M. (2000): Measurement of serum HA in patients with chronic $\mathrm{HCV} \&$ its relation to liver histology. Consensus Interferon study Group.J.Gastroenterol.Hepatol., 15:945-951.

63- Xie B Yao $L$ and Zheny $Q$. (2003): Hyaluronic acid, procollagen type III and IV histological diagnosis of liver fibrosis.HBPD Int. 2:69-72.

64- Lu G, Zeng $M$ and Wan $B$. (2003): Grading and staging of hepatic fibrosis and its relationship with noninvasive diagnostic parameters. World J. Gastroenterology 9(11): 25742578.

65- Friedman L. (2000): Molecular regulation of hepatic fibrosis, an integrated cellular response to tissue injury. J.Biol. Chem., 275 (4), 2247-2250.

66- Patel K, Lajoie A and Heaton S. (2003): Clinical use of hyaluronic acid as a predictor of fibrosis change hepatitis C. J.Gastroentero. Hepatol., 18:253257.

67- Abd-el Fattah M A, Toson A and EL-Waseef A. (2006):
Discriminate function based on hyaluronic acid and its degrading enzymes and degradation products for differentiating cirrhotic from non-cirrhotic liver diseased patients in chronic HCV infection. Clinica Chimica Acta 10189:7.

68- Drobnik J., Dabrowski R. (1999): Pinealectomy-induced elevation of collagen content in the intact skin is suppressed by melatonin application. Cytobios., 100 (393), 49-55.

69- Cunnane C., Manku S., Horrobin F. (1979): The pineal and regulation of fibrosis: pinealectomy as a model of primary biliary cirrhosis: roles of melatonin and prostaglandins in fibrosis and regulation of $\mathrm{T}$ lymphocytes. Medical Hypotheses 5 (4), 403-414.

70- Arslan O, Zerin M, Coskun A. (2002): The effect of melatonin on bleomycin-induced pulmonary fibrosis in rats. Journal of Pineal Research 32 (1), 21-25.

71- Peres W., Tunon J., Collado S., Herrmann S., Marroni N., Gonzalez J., (2000): The flavonoid quercetin ameliorates liver damage in rats with biliary obstruction. Journal of Hepatology 33 (5), 742-750.

72- Sigala1 F, Theocharis S, Sigalas1 $\mathrm{K}$, Kyroudis $\mathrm{S}$, Papalabros1 E. (2006): Therapeutic value of melatonin in an experimental model of liver injury and regeneration. J. Pineal Res., 40:270-279.

73- Theocharis S, Margeli A., Skaltsas S. (2001): Induction of metallothionein in the liver of 
carbon tetrachloride intoxicated rats: an immunohistochemical study. Toxicology 161:129-138.

74- Sigala F, Kostopanagiotou G, Andreadou I. (2004): Histological and lipid peroxidation changes after administration of 2acetylaminofluorene in a rat liver injury model following selective periportal and pericentral damage. Toxicology 96:155-163.

75- Sigala F, Kostopanagiotou G, Andreadou I. (2004): Histological and lipid peroxidation changes after administration of 2acetylaminofluorene in a rat liver injury model following selective periportal and pericentral damage. Toxicology 96:155-163.

76- Dang S, Wang B, Cheng Y, Song P, Guo Liu Z. (2007): Inhibitory effects of saikosaponin-d on $\mathrm{CCl}_{4}$-induced hepatic fibrogenesis in rats. World J Gastroenterol., 28; 13(4): 557-563.

77- Guha M, Maity P, Choubey V, Reiter J, Bandyopadhyay U. (2007): Melatonin inhibits free radical-mediated mitochondrialdependent hepatocyte apoptosis and liver damage induced during malarial infection. J Pineal Res., 43: 372-381.

78- Molpeceres V, Mauriz L, Mediavilla G, Gonz P, Barrio P, Gallego J. (2007): Melatonin is able to reduce the apoptotic liver changes induced by aging via inhibition of the intrinsic pathway of apoptosis. J Gerontol A Biol Sci Med Sci., 62: 687695.
79- Ozdemir D, Uysal N, Tugyan K, Gonenc S, Acikgoz O, Aksu I. (2007): The effect of melatonin on endotoxemia-induced intestinal apoptosis and oxidative stress in infant rats. Intensive Care Med., 33: 511-516.

80- Zararsiz I, Kus I, Ogeturk M, Akpolat N, Kose E, Meydan S. (2007): Melatonin prevents formaldehyde-induced neurotoxicity in prefrontal cortex of rats: an immunohistochemical and biochemical study. Cell Biochem Funct., 25: 413-418.

81- Andrabi A, Sayeed I, Siemen D, Wolf G, Horn F. (2004) Direct inhibition of the mitochondrial permeability transition pore: a possible mechanism responsible for antiapoptotic effects of melatonin. FASEB J.,18: 869871.

82- Esrefoglu M, Gül M, Hanifi M, Polat A, Selimoglu M. (2005): Protective effect of low dose of melatonin against cholestatic oxidative stress after common bile duct ligation in rats. World $\mathrm{J}$ Gastroenterol., 11: (13): 19511956.

83- Meki A, Abdel-Chaffar K, ElGibaly I. (2001): Aflatoxin B1 induces apoptosis in rat liver: protective effect of melatonin. Neuroendocrinol Lett; 22:417426.

84- Jou J, Peng T, Reiter J, Jou B, Wu Y, Wen T. (2004): Visualization of the antioxidative effects of melatonin at the mitochondrial level during oxidative stress- induced apoptosis in rat brain astrocytes. J Pineal Res., 37:55-70. 


\title{
تاثير الميلاتونين الوقائي من حدوث تليف الكبد المستحدث في الفئران باستخدام رباعي كلوريد الكربون (CCL4)
}

\author{
منس فاروق القرن \\ قسم الفسيولوجيا الطبية، كلية الطبـ جامعة أسبرن
}

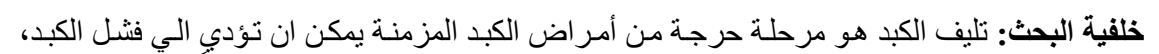

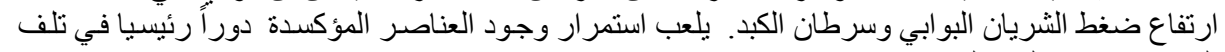
الخلايا وحدوث تليف الكبد.

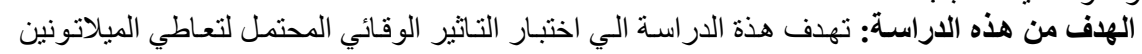

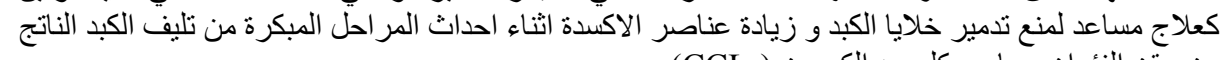

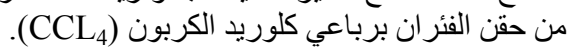

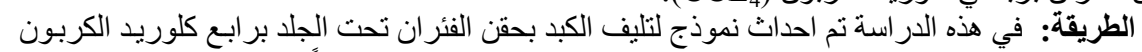

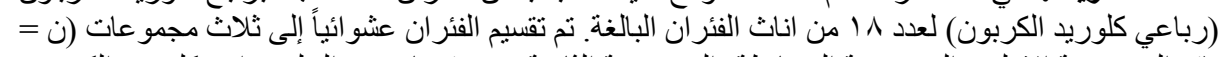

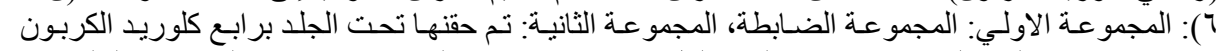

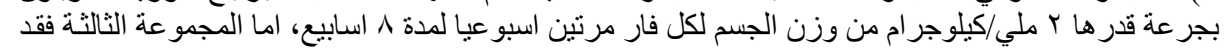

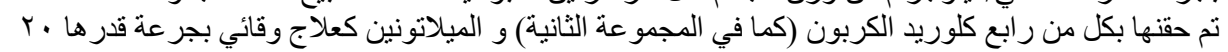

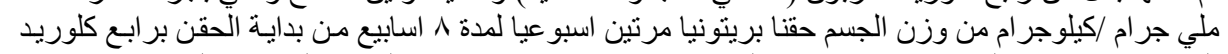

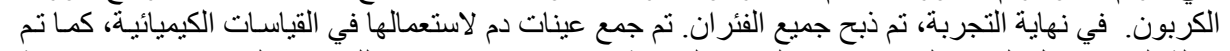

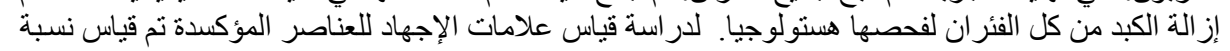

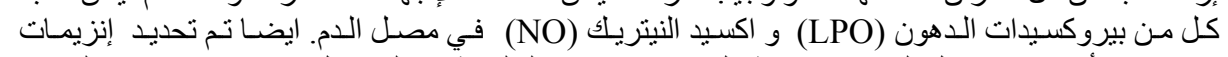

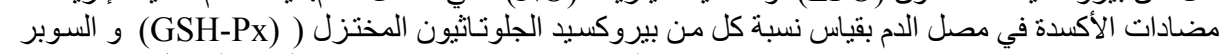

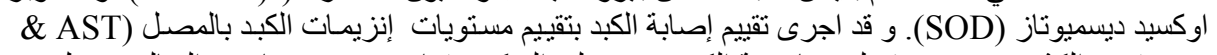

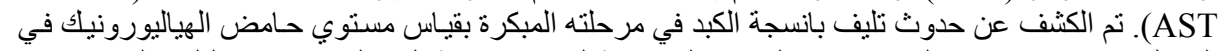

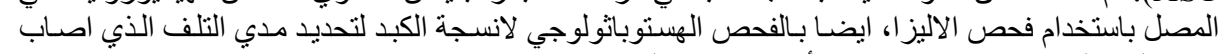

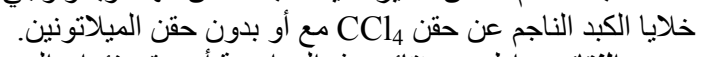

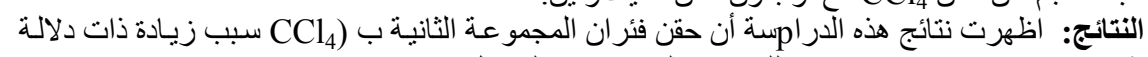

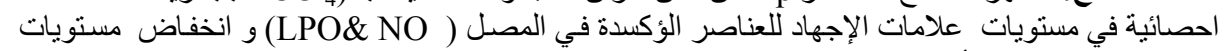

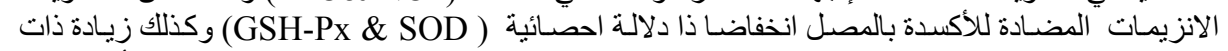

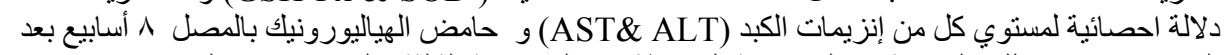

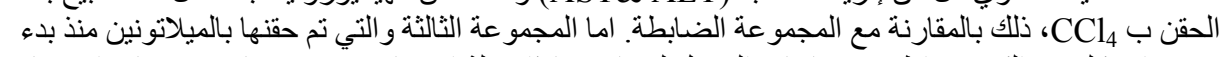

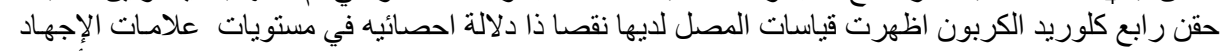

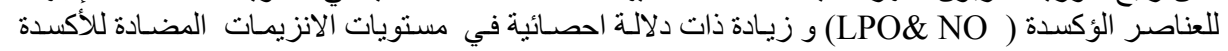

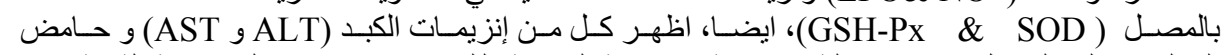

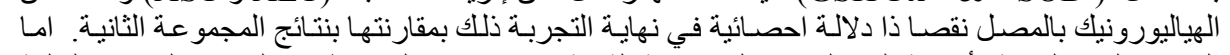

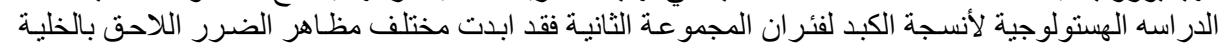

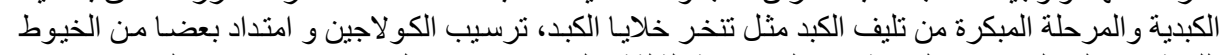

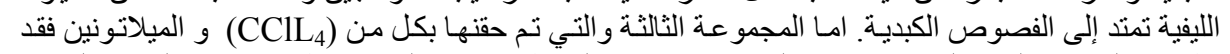

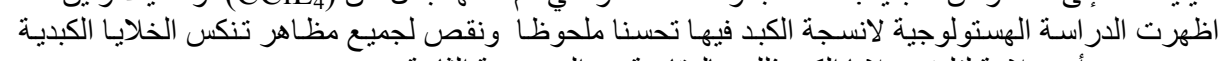

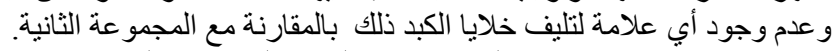

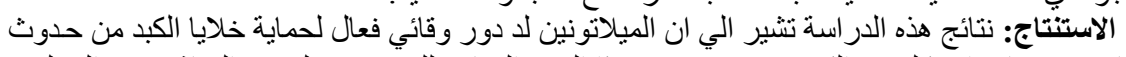
تليف بها بعد حقنها بر ابع كلوريد الكربون.

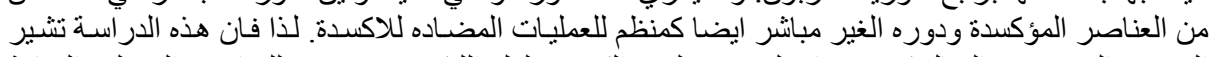

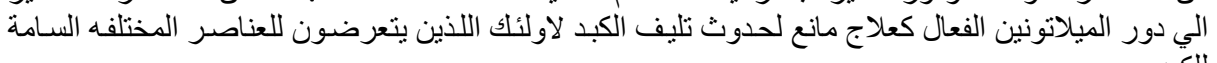

